Dicle Tıp Dergisi / Dicle Medical Journal (2018) 45 (2) : 173-178

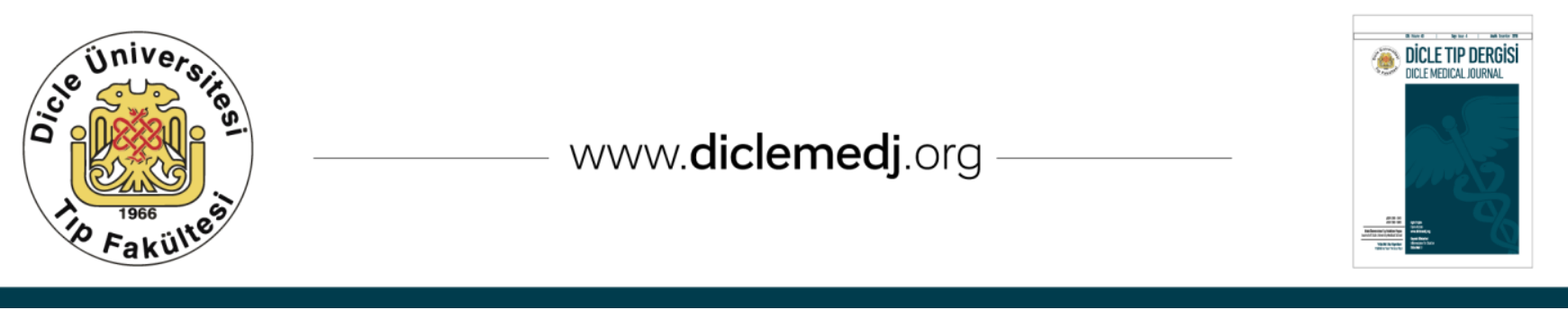

Özgün Araștırma / Original Article

\title{
Akut Subdural Hematomlu 106 Olgunun Retrospektif Değerlendirilmesi
}

\author{
Hüseyin Özevren1, Salih Hattapoğlu² \\ 1Dicle Üniversitesi Tıp Fakültesi, Beyin ve Sinir Cerrahisi Anabilim Dall, Diyarbakır, Türkiye. ORCID: 0000-0002-5437-4003 \\ 2 Dicle Üniversitesi Tıp Fakültesi, Radyoloji Anabilim Dal, Diyarbakır, Türkiye. ORCID: 0000-0003-4781-9729
}

Geliș: 11.12.2017, Revizyon: 08.03.2018, Kabul Tarihi: 22.03.2018

Öz

Amaç: ASDH (akut subdural hematom) olgularının klinik bulgularını ve bilgisayarlı tomografi sonuçlarını geriye dönük olarak değerlendirmek.

Yöntemler: Ocak 2013 -Mart 2017 yılları arasında kliniğimize başvuran 106 ASDH olgusu geriye dönük olarak incelendi. Her bir olgunun yaş, cinsiyet, subdural hematometiyolojisi, ve BT(bilgisayarlı tomografi) sonuçları değerlendirildi. Olguların beyin BT kesitlerindeki orta hat șifti, hematom hacmi ve dansitesi hesaplanarak incelendi. Sonuçlar istatistiksel olarak değerlendirildi.

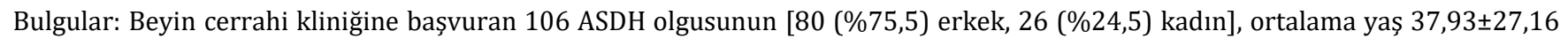
(1-89) idi. Olguların 65'i (\%61,3) kendiliğinden rezorbe oldu. Hastaların 23'ü $(\% 21,7)$ ameliyat edildi. Bununla beraber olgulardan, 12 'si $(\% 11,3)$ erkek ve 6’sı $(\% 5,6)$ kadın olmak üzere takiplerimiz esnasında eks olmuştur. Eks olguların kraniyal BT tetkiklerinde orta hat şiftine ek olarak kontüzyon, ödem veya diğer sistemik bulgular mevcuttu.

En sık başvuru nedenleri trafik kazaları 48(\%45), düşme 23(\%22), darp 14(\%13), ateşli silah yaralanması 11(\%10), spontan kanamalar 10(\%10) idi. Erkek ve kadın olgularda; hematom hacmi, dansitesi ve orta hat şifti açısından yapılan istatistiksel karşılaştırmada anlamlı farklılı bulunmadı. Olguların beyin tomografisi incelemesinde ortalama hematom hacimleri $22,54 \pm 2,45 \mathrm{~cm} 3$ (4-120), ortalama subdural hematomdansitesi 52,35 $\pm 15,12$ HU (Hounsfield Units) (18-76), orta hat şifti 2,34 $\pm 2,99 \mathrm{~mm}(0-17,25)$ olarak ölçülmüştür. Yaş ile subdural hematom hacmi arasında yapılan korelasyon testi pozitif yönde anlamlı bulundu $(\mathrm{p}<0,001, \mathrm{r}=0,425)$. Yaș ile hematomdansitesi arasındaki korelasyon testi negatif yönde anlamlı bulundu $(\mathrm{p}<0,05$, $r=-0,21)$.

Sonuç: Çalışmamızda, acil polikliniğimize başvuran ASDH'li hastaları etiyolojik, klinik ve radyolojik olarak değerlendirdik. Bu hastalar için kraniyal BT önemli tanı araçıdır. KraniyalBT'deASDH'e ek bulguların olması mortaliteyi önemli ölçüde arttırmaktadır. ASDH'lı hastalarda yaş arttıkça hematom hacmi artmakta ve dansitesi düşmekteydi. Yaşlı hastalarda küçük travmalar sonrasında da ASDH oluşabilmekte ve geç bulgu verebilmektedir.

Anahtar kelimeler: Akut subdural hematom, kafa travması, bilgisayarlı tomografi

DOI: $10.5798 /$ dicletip.410849

Yazışma Adresi / Correspondence: Hüseyin Özevren, Dicle Üniversitesi Tıp Fakültesi Beyin Cerrahi Kliniği, 21280, Diyarbakır, Türkiye e-mail: drozevren@gmail.com 


\title{
Retrospective Analysis of 106 Patients with Acute Subdural Hematoma
}

\begin{abstract}
Objective: Evaluation of the clinical findings and computed tomography results of patients with ASDH (acute subdural hematoma) retrospectively.

Methods: In this study, 106 patients admitted to our clinic with acute subdural hematoma between January 2013March 2017, were examined retrospectively. Each case was evaluated according to age, sex, etiology of subdural hematoma and computed tomography results. Computed tomography (CT) sections of the cases were examined by calculating in terms of midline shift, hematoma volume and densities. The results were evaluated statistically.

Results: Meanage of 106 acute SDH cases in neurosurgery care services were 37.93 \pm 27.16 (1-89), [80 (75.5\%) men, $26(24.5 \%)$ women]. Twenty three of patients $(21.7 \%)$ were operated. $65(61.3 \%)$ of the cases, had resorbed spontaneously. However, 12 (11.3\%) men and 6 (5.6\%) women patients died during our follow-up, who had contusion, edema,or other systemic findings in addition to the midline shift in cranial CT images. Most common reasons for application were traffic accident in 48 cases (45\%), falling in 23 cases (22\%), assault in 14 cases (13\%), gun fire injury in 11 cases (10\%) with, and 10 cases (10\%) with spontaneous bleeding. There was no statistical significance in comparison between men and women in terms of hematoma volume-density and midline shift. Mean volume of hematoma was $22.54 \pm 2.45 \mathrm{~cm} 3(4-120)$, mean density of subdural hematoma was $52.35 \pm 15.12 \mathrm{HU}$ (Hounsfield Units) (18-76), midline shift was $2.34 \pm 2,99 \mathrm{~mm}(0-17.25)$ in cases on brain tomography. There was a positive correlation between age and subdural hematoma volume statistical evaluation $(\mathrm{p}<0.001, \mathrm{r}=0.425)$. There was a negative correlation between the age and the assessment of hematoma density $(\mathrm{p}<0.05, \mathrm{r}=-0.21)$.

Conclusions: In our study, we evaluate patients applied to our clinic with ASDH, in terms of etiology, clinical and radiologically. Cranial CT is an important diagnostic tool for these patients. In cranial CT, additional findings in ASDH significantly increase mortality. In patients with ASDH, as age increased, hematoma volume increased and densities decreased. In elderly patients, ASDH may develop after minor trauma and symptoms may appear late.
\end{abstract}

Keywords: Acute subdural hematoma, head trauma, computed tomography.

\section{GíRIŞ}

Subdural hematomlar, dura ve araknoidmembranlar arasında subdural aralıkta gelişen ve radyolojik olarak konkav(yarım ay) șeklindeki kanamalardır ${ }^{1,2}$. Kanamanın kaynağı, dura yırtılmasına ve içerdiği venöz sinüslerin ya da asıcı venlerin hasarlanmasına bağlı olabilir. Beraberinde parankimal hasar ve intraparankimal hematom görülebilmektedir. Ağır travma olgularında parankimal arter laserasyonuna bağlı arteryel SDH da gelişebilir ${ }^{3}$. ASDH olgularının medikal olarak tedavi edilebilmesi için SD hematomun nörolojik defisite yol açan beyin basısına neden olmaması ve klinik durumun stabil olması gerekmektedir. Akut beyin şişmesi kompresyon etkisi ile hematomun büyümesine engel olur ve rezolüsyon görülebiliri,4,5. ASDH'ninrezorbe olabileceği düşünülerek, tam teşekküllü hastanelerde hastaların nörolojik muayenesi ve BT tetkikleri göz önünde bulundurularak, hastalar yakın medikal ve radyolojik takibe alınmalıdır ${ }^{4,6,7}$. Bu çalışmamızda kliniğimize başvuran ASDH (akut subdural hematom) olgularının klinik ve bilgisayarlı tomografi sonuçlarını geriye dönük olarak değerlendirerek, hematom hacmi-dansitesi ile yaş ve cinsiyet ilişkisini ortaya koyarak literatüre katkı sunmayı hedefledik. Olgularımızda subdural hematom etiyolojisi ve prognostik faktörleri veriler ışığında değerlendirerek, yüksek morbidite ve mortalite ile seyredebilecek bu hasta grubunda yeni yazılımlarla hesaplanabilen kantitatif bilgisayarlı tomografi ölçüm yöntemlerinin kullanılabilirliğine dikkat çekmeye çalıştık. 
Tablo 1: Hastaların bașvuru nedenleri

\begin{tabular}{|ll|}
\hline & Sayı $\%$ \\
\hline Trafik kazası & 4845 \\
Düşmeler & 2322 \\
Darp & 1413 \\
Ateşli silah yaralanması & 1110 \\
Spontan kanamalar & 1010 \\
\hline
\end{tabular}

Tablo 2: Çalıșma grupları ile ilgili istatistiksel sonuçlar

\begin{tabular}{|llll|}
\hline & Erkek & Kadın & $\mathrm{p}$ \\
\hline Hematomdansitesi $(\mathrm{HU})$ & $51.71 \pm 15.27$ & $54.31 \pm 14.77$ & $\mathrm{p}=0.444$ \\
Ortahat şifti $(\mathrm{mm})$ & $2.43 \pm 3.25$ & $2.07 \pm 2.05$ & $\mathrm{p}=0.512$ \\
Hacim $\left(\mathrm{cm}^{3}\right)$ & $22.18 \pm 21.05$ & $23.65 \pm 23.06$ & $\mathrm{p}=0.773$ \\
\hline
\end{tabular}

Ortalama \pm Standart sapma, student t testi

Tablo 3: Çalıșma grupları ile ilgili istatistiksel sonuçlar

\begin{tabular}{|c|c|}
\hline & Yaș $(37.93 \pm 27.16)$ \\
\hline Hematomdansitesi (HU) $(52.35 \pm 15.12)$ & $\mathrm{p}<0.05$ \\
\hline Hacim $\left(\mathrm{cm}^{3}\right)(22.54 \pm 2.45)$ & $\mathrm{p}<0.001$ \\
\hline
\end{tabular}

Ortalama \pm Standart sapma, pearsonkorelasyon testi

Tablo 4:Eks olan olgularda Subduralhematom dişındaki BT bulguları

\begin{tabular}{|lc|}
\hline & Olgu \\
\hline Epiduralhematom, kırık & 2 \\
Masif serebral ödem & 2 \\
Kontüzyon, masif ödem, kırık & 2 \\
Parenkimalhematom, kontüzyon, SAK & 3 \\
Epiduralhematom, kırık, SAK & 1 \\
Epiduralhematom, kontüzyon, kırık, SAK & 1 \\
MSS dışı travmatik hasar & 5 \\
\hline
\end{tabular}

16

*Eks olan 2 hastada BT'de izole subduralhematom mevcuttu 

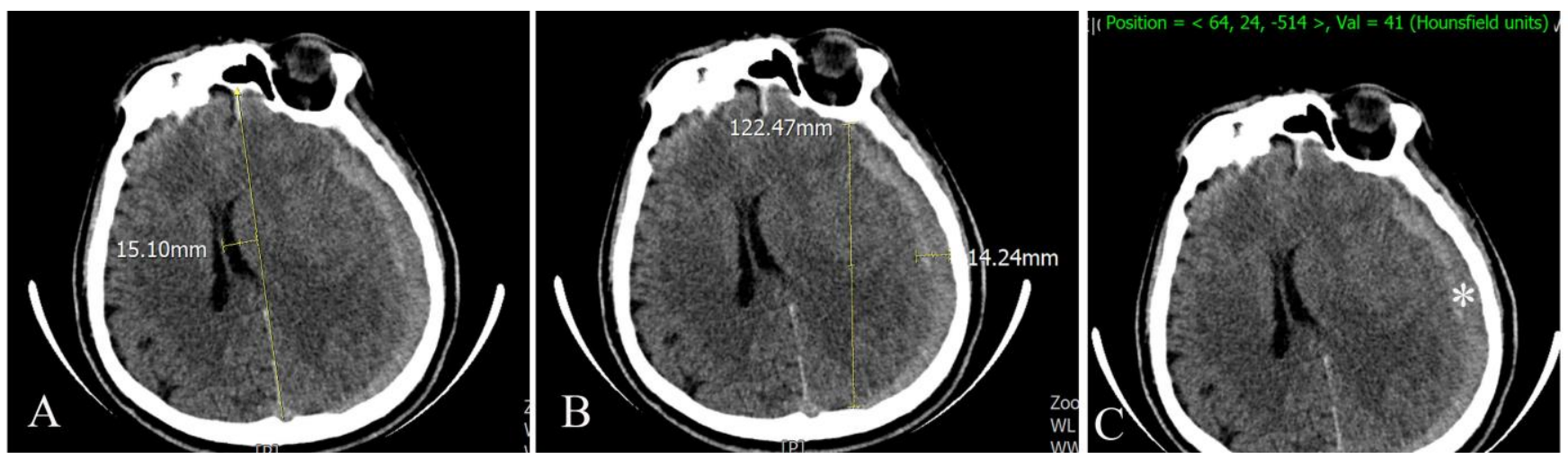

Resim 1:ASDH'li olgunun BT kesitsel görüntü ve ölçümleri. Yüksekten düşme sonrası acil polikliniğe getirilen 60 yaşındaki ASDH'li erkek hastanın beyin tomografisindeki yapılan ölçümler. A) ortahat şifti B) hematom hacmi C) hematomdansitesi'nin hesaplanması gösterilmiştir.

\section{YÖNTEMLER}

Ocak 2013 - Mart 2017 yılları arasinda kliniğimize başvuran 106 ASDH olgusu retrospektif olarak değerlendirildi. Bilgisayarlı tomografi görüntüleri 64-dedektörlü-row Philips Brilliance CT scanner (Philips MedicalSystems, Cleveland, $\mathrm{OH}$ ) ve16dedektörlü Toshiba Activion V3.00 CT scanner (Toshiba Medical Sytems, Tokyo, Japan) ile elde edildi. Olguların BT görüntüleri radyolojik iş istasyonunda (INFINITT; Infinitt Health care, Seoul, Korea) beyin cerrahisi uzmanı (H.Ö) veBT konusunda deneyimli bir uzman nöroradyolog (S.H) tarafindan değerlendirilerek, ölçümler yapıldı.

Veriler ortalama \pm standart sapma (min-max) olarak sunularak, çözümlenmesinde SPSS 18 (Chicago, Illinois, USA) programı kullanılmıştır. Her bir olgunun yaş, cinsiyet, subduralhematom etiyolojisi, mortalite ve iyileşme durumları ile birlikte, beyin BT (bilgisayarlı tomografi) kesitleri değerlendirilerek orta hat şifti8, hematom hacmi9ve dansitesi10 hesaplandı. Araştırmada elde edilen veriler cinsiyetleri arasında farklılık olup olmadığını belirlemek için "student t" testi, yaşları bakımından farklılık olup olmadığını belirlemek için pearson korelasyon analizi yapıldı.

\section{BULGULAR}

Ocak 2013-Mart 2017 yılları arasında beyin cerrahi kliniğine başvuran 106 ASDH olgusu değerlendirildiğinde vakaların 80'i $(\% 75,5)$ erkek, 26'sı $(\% 24,5)$ kadındı. Ortalama yaş 37,93 $\pm 27,16$ (1-89) idi. En sık başvuru nedenleri; trafik kazaları 48 (\%45), düşmeler 23 (\%22), darp 14 (\%13), ateşli silah yaralanmaları $11(\% 10)$, spontan kanamalar 10 (\%10) olarak tespit edildi (tablo 1). Erkekler ve kadınlarda hematom hacmi, dansitesi ve orta hat şifti açısından yapılan istatistiksel karşılaştırmada anlamlı farklılık bulunmadı (tablo 2).

Olguların beyin tomografisindeki ortalama hematom hacimleri 22,54 $\pm 2,45 \mathrm{~cm} 3$ (4-120), ortalama subdural hematomdansitesi $52,35 \pm 15,12$ HU (18-76), orta hat şifti $2,34 \pm 2,99 \mathrm{~cm} \quad(0-17,25) \quad$ olarak ölçüldü (Resim1).

Yaş ile hematom hacmi arasında yapılan korelasyon testi pozitif yönde anlamlı bulundu $(\mathrm{p}<0,001, r=0,425)$. Yaş ile hematomdansitesi arasındaki korelasyon testi negatif yönde anlaml bulundu $(\mathrm{p}<0,05, \mathrm{r}=-0,21)$ (tablo 3$)$. ASDH'li hastalarda yaş arttıkça hematom hacmi artmakta ve dansitesi düşmekteydi.

$\mathrm{Bu}$ hastaların 23'ü $(\% 21,7)$ ameliyat edildi. Olguların 65'i $(\% 61,3)$ kendiliğinden rezorbe 
oldu. Bununla beraber olgulardan, 12'si $(\% 11,3)$ erkek ve 6 'sı $(\% 5,6)$ kadın olmak üzere takiplerimiz esnasında eks olmuştur. Eks olguların kraniyal BT tetkiklerinde orta hat şiftine ek olarak kontüzyon, ödem veya diğer sistemik bulguları mevcuttu (tablo 4).

\section{TARTIŞMA}

Beyin yüzeyinden dural sinüslere uzanan köprü venlerin yırtılmasından kaynaklanan dura ve araknoidmembran arasındaki kanamalar SDH olarak adlandırılır. Bazen \%20-30 vakada arteryelrüptürden de kaynaklanabilir. ASDH'li hastaların \%11'inde hafif ve orta düzeyde travmatik beyin hasarı mevcuttur. Travmatik beyin hasarına bağlı kan-beyin bariyeri yıkılmakta, beyin ödemi ve intrakraniyal basınç artmakta, bu da SDH için tampon görevi oluşturmaktadır. Düşük basınçlı venöz kanamadan kaynaklanan SDH'li çoğu olgu yükselen intrakraniyal basınç ve klottamponatından dolayı durur. Bazı vakalarda spontan ASDH meydana gelebilmektedir. Spontan ASDH nedenleri arasında antikoagülan ve antiplatelet ilaç kullanımı, anevrizma rüptürü, vaskülermenenjiom, venözmalformasyon, dural metastaz, intrakraniyal hipotansiyon siralanabilir ${ }^{11,12}$.

Kafa travmalarında ASDH olabileceği unutulmamalı ve ilk tercih edilen görüntüleme yöntemi BT olmalıdır. Radyasyona maruziyet riski nedeniyle kullanımı tartışmalı olmakla birlikte kolay uygulanabilir, sonuçları güvenilir bir yöntem olması nedeniyle, ayrıca kalıcı nörolojik defisit ve ölümcül olabilen bir intrakraniyal hasarı atlamamak için değerlendirmede hala ilk sıradaki yerini korumaktadır ${ }^{2,6}$.

Wilberger ve arkadaşlarının yapmış olduğu çalışmada ASDH olgularının en sık iki sebebinin trafik kazaları ve düşmeler olduğu belirtilmiştir ${ }^{13}$. Çalışmamızda ASDH etiyolojisinde benzer şekilde trafik kazaları ve düşmeler en sık sebebi oluşturmakta olup sonrasında ateşli silah yaralanması, darp ve spontan kanamalar görüldü (tablo 1).

Wilberger ve arkadaşları ASDH olgularının \%60 kadarı klinik takiplerinde kendiliğinden rezorbe olduğunu belirtmişlerdir ${ }^{13}$. Bunun nedenleri olarak, kafa içi basınçının kompresyon etkisi ile hematomun büyümesine engel olması 1,5,14, bir diğeri travma sırasında oluşan araknoid membrandaki yırtık sayesinde BOS'unhematomu yıkaması ve drenajını sağlamasıdır ${ }^{6}$. Biz de yaptığımız çalışmada olgularin 65 'inde $(\% 61,3)$ hematomun kendiliğinden rezorbe olduğunu gördük. ASDH olgularında ek bulguların olması mortaliteyi önemli derecede arttırmaktadır ${ }^{4,6,13}$, Çalışmamızda ASDH'li olgulardan 12'si (\%11,3) erkek ve 6'sı $(\% 5,6)$ kadın olmak üzere, takiplerimiz esnasında eks olmuştur. $\mathrm{Bu}$ hastaların kraniyal BT tetkiklerinde orta hat şiftine ek olarak kontüzyon, ödem veya diğer sistemik bulguları mevcuttu (tablo 4).

Yaşlı hastalarda beyin hacmi azaldığından, hematom hacmi büyük boyutlara gelmedikçe beyinde herhangi bir itilmeye ve nörolojik bozukluğa sebep olmaz. Köprü venlerdeki yırtılma ve kopmalardaki sızıntılar günler içinde alanı dolduracağından hastalar genelde subakut dönemde hematomdansitesi azalmış (hematomun çökelmesine bağlı) şekilde başvurur ${ }^{2,6}$. Literatürde ortalama yaşın 64 olduğu ve olguların \%80'ninin 50 yaşın üzerinde olduğu bildirilmiştir ${ }^{15,16}$. Bizim çalışmamızda da yaş arttıkça hematom hacminin artması ve dansitenin azalmasıbu çalışmalarla uyumluydu (tablo 3). Subakut süreçte SDH olgularında çoğunlukla önemsenmeyen kafa travması bulunmaktadır. Genellikle hastalar geçirdikleri travma veya travmaları unutmuşlardır ${ }^{15,16}$. Çalışmamızda da benzer şekilde 65 yaş üstü 24 ASDH hastasının \%70'i subakut dönemde gelmişti. Bu hastalar travma geçirip geçirmediklerini hatırlamamaktaydı ve yakınları tarafindan konuşma bozukluğu, yürümede dengesizlik, 
oryantasyon bozukluğu şikayetleri ile kliniğimize başvurmuşlardı.

Subdural hematomdansitesi hakkında yapılan çalışmalar daha çok hematomdansitesi ve postoperatif hematom rekürrensi ilişkisi ortaya konulmaya çalışılmıştır9-10,17. Bu çalışmalarda hematomdansitesi arttıkça post-operatif rekürrensin arttığl bildirilmiştir. Biz çalışmamızda hematomdansitesini rekürrens açısından değil, farklı olarak cinsiyet-yaşhematom hacmi açısından değerlendirdik. Travmanınetiyolojisi ne olursa olsun erkekler ve kadınlarda hematom hacmi, dansitesi açısından fark yoktu (tablo 2).

Sonuç olarak, bu çalışmada kliniğimize başvuran ASDH'li hastaları etiyolojik, klinik ve radyolojik olarak değerlendirdik. Bu hastalar için kraniyal BT önemli tanı aracıdır. Kraniyal BT'de ASDH'e ek bulguların olması mortaliteyi önemli ölçüde arttırmaktadır. Yaşlı hastaların daha fazla hematom hacmiyle ve daha geç bulgu verdiklerinden, düşük dansiteli olarak subakut dönemde tespit edilebileceği düşünülmeli; tanı ve takip süreçlerinde travma anamnezinden bahsetmeyen nörolojik şikayetlerle başvurmuş hastalarda, subakut süreçte SDH olabileceği unutulmamalıdır.

Çıkar Çatışması Beyanı: Yazarlar çıkar çatışması olmadığını bildirmişlerdir.

Finansal Destek: Bu çalışma her hangi bir fon tarafından desteklenmemiștir.

Declaration of Conflicting Interests: The authors declare that they have no conflict of interest.

Financial Disclosure: No financial support was received.

\section{KAYNAKLAR}

1. Lee $\mathrm{CH}$, Kang DH, Hwang SH, et al. Spontaneous rapid reduction of a large acute subdural hematoma. J Korean Med Sci. 2009; 24:1124-6.

2. Lee SH, Rao KCVG, Zimmerman RA. Cranial MRG and CT, 4th edn. New York: McGrawHill, 2004.

3. Cohen JE, Eger K, Montero A, et al. Rapid spontaneous resolution of acute subdural hematoma and HIV related cerebral atrophy: Case report. Surg Neurol. 1998; 50:241-4.

4. Matsuyama T, Shimomura T, Okumura Y, et al. Rapid resolution of symptomatic acute subdural hematoma. Case report. Surg Neurol. 1997; 48:193-6.

5. Duman H, Ziyal Mİ, Türkmenoğlu 0, et al. Early spontaneous resolution of symptomatic acute subdural hematoma: A childhood case. Türk Nöroşirurji Dergisi 2001; 11:222-5.

6. Zhuang Z, Luo J, Ou C, et al. The clinical and CT features of rapid spontaneous resolution of traumatic acute subdural hematoma: A retrospective study of 14 cases. Brain Inj. 2015; 17:1239-45.

7. Özkan Ü, Kemaloğlu S,Özateș M, Güzel A, Tatlı M. Analyzing extradural haematomas: A retrospective clinical investigation. Dicle Tıp Dergisi, 2007; 34:14-9.

8. Missori P, Morselli C, Domenicucci M, et al. Measurement of bone flap surface area and midline shift to predict overall survival after decompressive craniectomy. World Neurosurg. 2016; 96:11-4.

9. Xu FF, Chen JH, Leung GK, et al. Quantitative computer tomography analysis of post-operative subdural fluid volume predicts recurrence of chronic subdural haematoma. Brain Inj. 2014; 28:1121-6.

10. Lin CC, Lu YM, Chen TH, et al. Quantitative assessment of post-operative recurrence of chronic subdural haematoma using mean haematoma density. Brain Inj. 2014; 28:1082-6.

11. Al-Mufti F, Mayer SA. Neurocritical care of acute subdural hemorrhage. Neurosurg Clin N Am. 2017; 28:267-78.

12. Ozevren H, Irtegun S, Deveci E, et al. Neuroprotective effects of potentilla fulgens on traumatic brain injury in rats. Anal Quant Cytopathol Histpathol. 2017; 39:35-44.

13. Wilberger JE Jr, Harris M, Diamond DL. Acute subdural hematoma: Morbidity, mortality, and operative timing. J Neurosurg. 1991; 74:212-8.

14. Arıkanoğlu A, Hünkar R, Çınar K. Bilateral subdural hematoma bağlı parkinsonism/ Parkinsonism secondary to bilateral subdural hematoma. Dicle Tip Dergisi 2011; 38:247-9

15. Camel M, Grubb RL Jr. Treatment of chronic subdural hematoma by twist-drill craniotomy with continuous catheter drainage. J Neurosurg. 1986; 65:183-7.

16. Richter HP, Klein HJ, Schafer M. Chronic subdural haematomas treated by enlarged burr hole craniotomy and closed system drainage. Retrospective study of 120 patients. Acta Neurochir. 1984; 71:179-88.

17. Kung WM, Hung KS, Chiu WT, et al. Quantitative assessment of impaired postevacuation brain reexpansion in bilateral chronic subdural haematoma: Possible mechanism of the higher recurrence rate. Injury 2012; 43:598-602 